\title{
Preparation of an efficient humidity indicating silica gel from rice husk ash
}

\author{
J P NAYAK and J BERA* \\ Department of Ceramic Engineering, National Institute of Technology, Rourkela 769 008, India
}

MS received 6 May 2009; revised 25 September 2010

\begin{abstract}
An efficient humidity indicating silica gel was prepared using rice husk ash as a raw material via sodium silicate extraction and acid neutralization method. Cobalt chloride was impregnated into the silica gel as a colour indicating material. A low concentration of cobalt chloride solution $\left(0.0005 \mathrm{~mol} \mathrm{dm}^{-3}\right)$ was used for the impregnation. The effect of $\mathrm{pH}$ of the impregnating solution on the colour development behaviour of the gel was investigated. The specific surface area of the gel was determined by Brunauer-Emmett-Teller method. The gel has been characterized using X-ray diffraction, scanning electron microscopy and visible spectroscopy. The moisture adsorption and desorption kinetics of the desiccant were evaluated using simultaneous thermogravimetry and differential scanning calorimetry.
\end{abstract}

Keywords. Silica gel; humidity; rice husk ash; cobalt.

\section{Introduction}

Silica gel desiccant is used to protect sensitive materials from damage due to humidity. Since the gel is normally white or colourless and shows no changes of colour during use, it is difficult to tell when it becomes saturated with moisture and needs to be regenerated or to be replaced. Therefore, a visible indication is necessary to know when the gel is saturated with moisture. Traditionally this has been achieved by impregnating the gel with cobalt salt, usually chloride (Balkose et al 1998), which imparts a deep blue colour to the dry gel. The colour of the dry gel changes from blue to light pink upon water vapour adsorption. This sharp colour changing property makes it a most popular desiccant for different industrial applications.

The silica gel is normally prepared from commercially available sodium silicate. The sodium silicate is manufactured by smelting quartz sand with sodium carbonate at $1300^{\circ} \mathrm{C}$ (Iler 1979; Brinker and Scherer 1990). The process is expensive due to its high temperature requirement. On the contrary, sodium silicate can be prepared at much lower temperature by simply boiling the amorphous silica in sodium hydroxide solution. A cheap source of amorphous silica is the rice husk ash (RHA). Thus, RHA is used as an economic raw material for the production of sodium silicate (Lender and Ruiter 1990; Luan and Chou 1990; Krishnarao and Godkhindi 1992; Kamath and Proctor 1998).

\footnotetext{
*Author for correspondence (jbera@ rediffmail.com)
}

RHA is a waste product generated by the energy producing units which uses the husk as a fuel (Kalapathy et al 2000). It has also been used by many workers to derive silica (Cunha and Canepa 1986; Conradt et al 1992; Real et al 1996; Yalcin and Sevinc 2001; Liou 2004; Ahmed and Adam 2007; Goncalves and Bergmann 2007). In the present work, RHA waste material was collected from a local industry and was used to synthesize silica gel via sodium silicate extraction and acid neutralization method.

A sharp colour change in a small humidity range is desired for an efficient indicating gel. The blue colour intensity of the dry gel directly depends on the weight fraction cobalt salt present in it and uniform dispersion of the salt in the gel. The more the homogeneous dispersion of cobalt salt, the lower will be the amount required to obtain the same colour intensity in the gel. Another objective of this work was to use cobalt concentration as minimum as possible for the interest of health and safety of the desiccant application. The effects of gel washing and effect of $\mathrm{pH}$ during cobalt impregnation on the colour development behaviour of the gel were investigated. The moisture adsorption capacity and the regeneration characteristic of the desiccant were also investigated.

\section{Experimental}

RHA was collected from a local rice mill. Sodium hydroxide (Laboratory Grade, Loba, India), hydrochloric acid (Loba, India) and $\mathrm{CoCl}_{2} \cdot 6 \mathrm{H}_{2} \mathrm{O}$ (Laboratory Grade, Loba, India) were used for the preparation of indicating silica gel. RHA was thoroughly washed with water before 
use. Typically, $5 \mathrm{~g}$ dry ash was boiled in $100 \mathrm{ml} 1 \mathrm{M}$ $\mathrm{NaOH}$ solution for $1 \mathrm{~h}$ under reflux condition to dissolve amorphous silica as sodium silicate. The solution was then filtered to separate residue. After cooling to room temperature, the sodium silicate solution was added drop wise into $1 \mathrm{~N} \mathrm{HCl}$ solution with constant stirring condition. The $\mathrm{pH}$ of the final solution was maintained at 5 . Within a few minutes, the sol turned into gel. The gel was broken and washed with water for several times to remove sodium and chlorine ions.

The washed hydrogel was then aged in $0.0005 \mathrm{~mol} \mathrm{dm}^{-3}$ $\mathrm{CoCl}_{2}$ aqueous solution at different $\mathrm{pH}$ for 6 days. In separate experiments, the gel was aged at $\mathrm{pH} \mathrm{2,4,6,8}$ and 10 respectively. The aged hydrogel was then separated by filtration and dried at $150^{\circ} \mathrm{C}$ till it attained constant weight. The dry desiccant was then aged in $90 \%$ relative humidity $(\mathrm{RH})$ for 1 day and then re-dried at $150^{\circ} \mathrm{C}$ to get homogeneous distribution of cobalt salt on the surface of the silica gel.

The washed and unwashed gels were characterized by X-ray diffraction (XRD) using PW1830 diffractometer, Philips, Holland. The microstructures of selected specimen were studied by using scanning electron microscope (SEM, JSM-6480LV). Fourier transform infrared (FTIR) data of selected specimen were obtained using Perkin Elmer FTIR spectrophotometer (Spectrum RX-1). The visible spectra of the gel were collected in Perkin Elmer UV-visible spectrophotometer (Lambda 35). The specific surface area of the gel was determined by the BrunauerEmmett-Teller (BET) method using Autosorb-1, Quantachrome surface area analyzer. The humidity adsorption capacity of the desiccant was measured in $80 \% \mathrm{RH}, 30^{\circ} \mathrm{C}$. The dehydration (regeneration) characteristic of the desiccant was evaluated using thermogravimetric analysis and differential scanning calorimetry (TGA/DSC, Netzsch STA $449 \mathrm{C}$ Jupitor) with a $10^{\circ} \mathrm{C} / \mathrm{min}$ heating rate under $\mathrm{N}_{2}$ gas.

\section{Results and discussion}

The colour changing behaviour of $\mathrm{CoCl}_{2}$ impregnated silica gel depends on many parameters like chemical composition of the gel, concentration of indicating salt, $\mathrm{pH}$ of processing condition, drying, relative humidity, etc. Figure 1 shows XRD patterns of different silica gel powder in their dry state. Unwashed gel (figure 1(a)) shows the presence of $\mathrm{NaCl}$ and $\mathrm{Na}_{2} \mathrm{SiO}_{3}$ crystalline phases. Due to their presence, unwashed gel appears translucent and whitish in colour after drying. Figure 1(b) shows the pattern for properly washed gel which is not impregnated with $\mathrm{CoCl}_{2}$. The pattern of impregnated gel (figure 1(c)) is very similar to that of un-impregnated gel. Both the materials show typical amorphous silica XRD pattern. There are no peaks of $\mathrm{CoCl}_{2}$ in the impregnated gel due to its low concentration, i.e. the concentration was below the detection limit of X-ray powder diffraction measurement.

Figure 2 shows SEM morphology of unwashed and washed gel. The granular morphology of unwashed gel (figure 2(a)) was due to the presence of $\mathrm{NaCl}$ on the surface. During drying of the gel, dissolved $\mathrm{NaCl}$ comes to the surface along with water and forms granular microstructure. Those granules were absent in washed gel (figure 2(b))

The colour development behaviour of impregnated silica gel after drying was dependant on the $\mathrm{pH}$ of impregnation mixture. Figure 3 shows the colours of different gels at their dry state (top row) and after their humidification (bottom row). The $\mathrm{pH}$ shown in the figure, indicates the equilibrium $\mathrm{pH}$ of hydrogel plus $\mathrm{CoCl}_{2}$ solution during aging. All the specimens were aged with same concentration of $\mathrm{CoCl}_{2}$ solution. The figure shows that the blue colour of dry gel became faint increasingly with the lowering of $\mathrm{pH}$. It also shows that $\mathrm{pH} 6$ gel has most prominent blue to pink colour changing behaviour. The $\mathrm{Co}(\mathrm{II})$ has tetrahedral $\left[\mathrm{CoCl}_{4}\right]^{2-}$ complex structure in dry state, which is deep blue in colour. Upon exposure to moisture the structure changes to the octahedral $\left[\mathrm{Co}\left(\mathrm{H}_{2} \mathrm{O}\right)_{6}\right]^{2+}$ complex, which is pink in colour (Richardson 1993).

pH 2 gel was nearly colourless in both dry and humidified state. This may be due to low adsorption of cobalt on the gel as the isoelectric point of silica is near $\mathrm{pH}$ 2. The colour of $\mathrm{pH} 10$ gel was reddish-brown. The ammonium hydroxide was used to raise $\mathrm{pH}$ of the impregnation mixture. At higher concentration of ammonia addition, $\mathrm{H}_{2} \mathrm{O}$-ligand of cobalt complex is replaced by

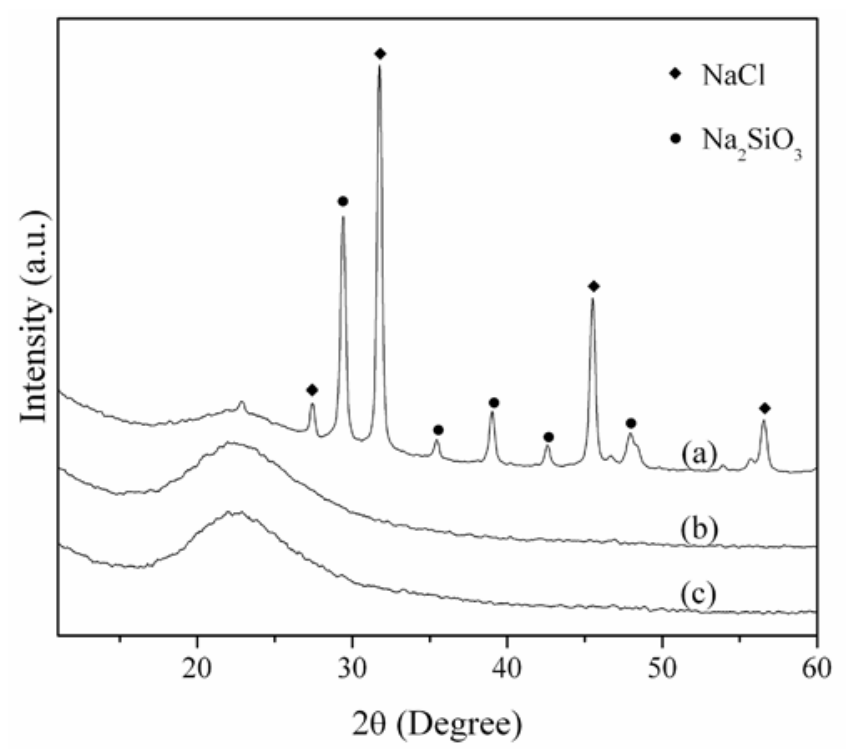

Figure 1. X-ray diffraction patterns for unwashed (a), washed un-impregnated (b) and $\mathrm{CoCl}_{2}$ impregnated silica gel (c). 

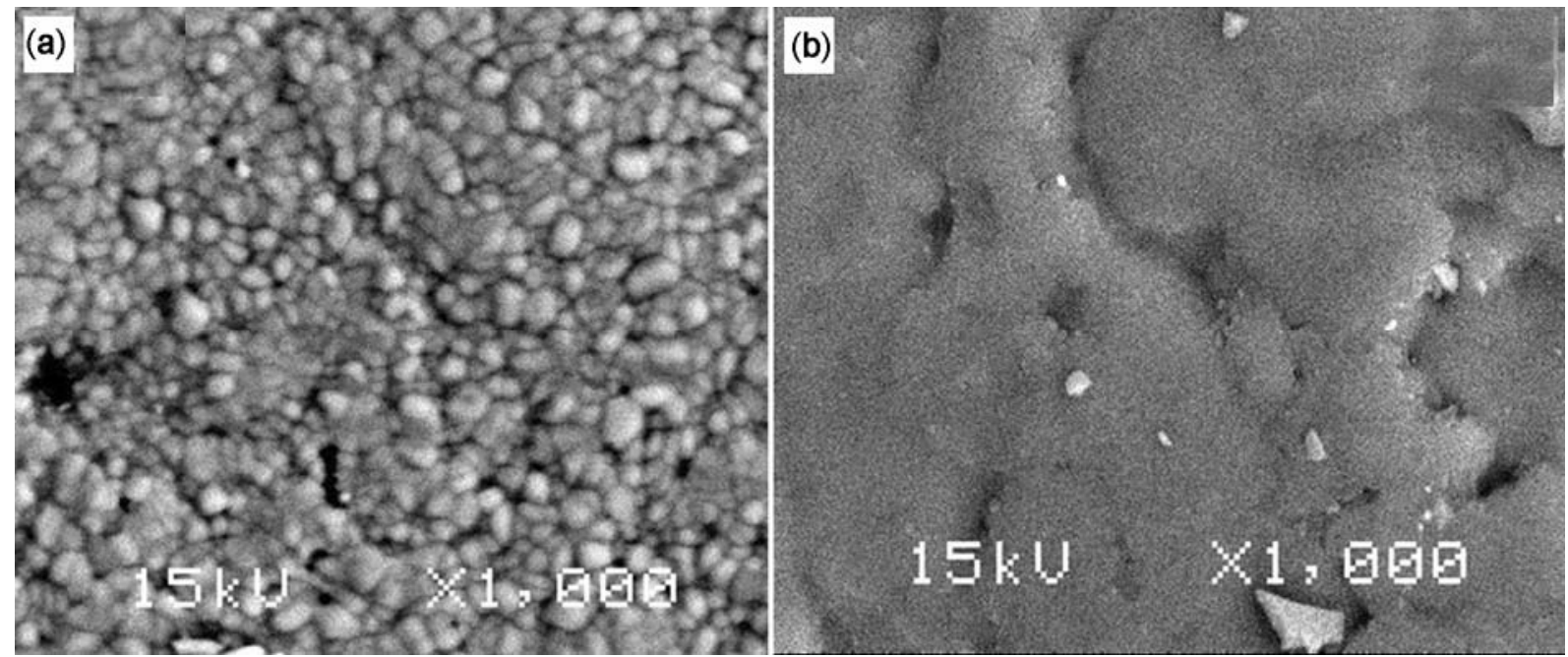

Figure 2. SEM photographs of (a) unwashed and (b) washed silica gel.

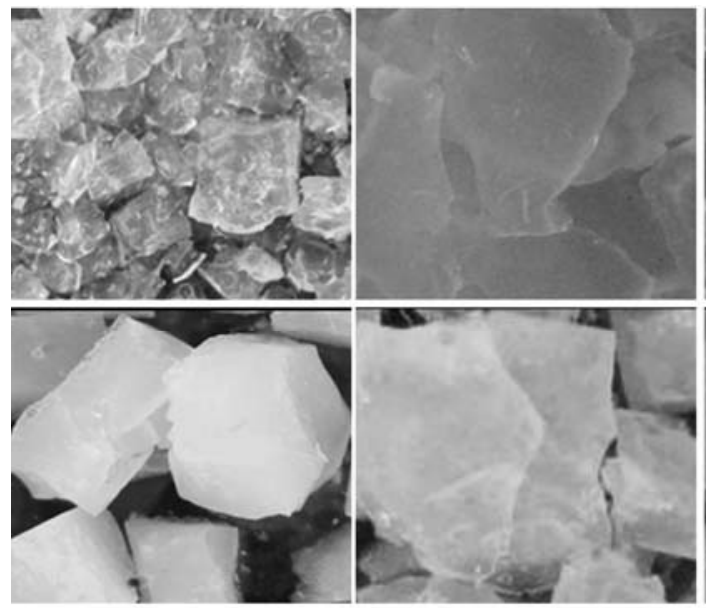

$\mathrm{pH} 2$

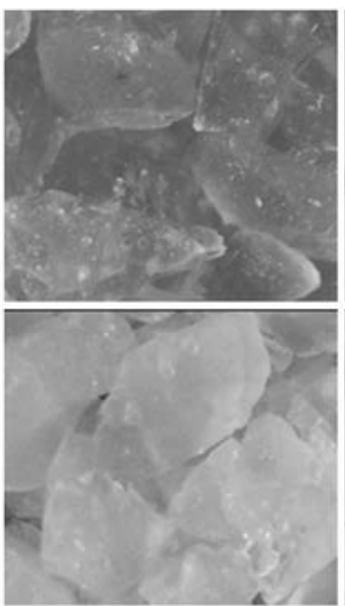

$\mathrm{pH} 6$

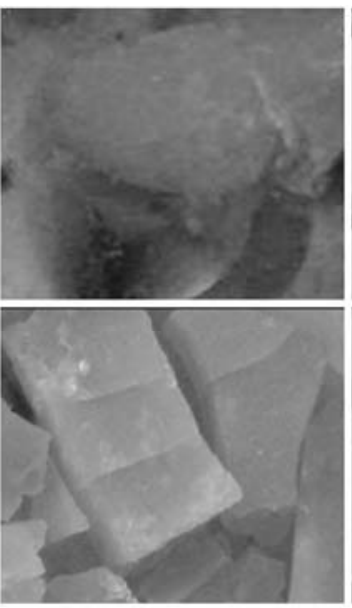

$\mathrm{pH} 8$

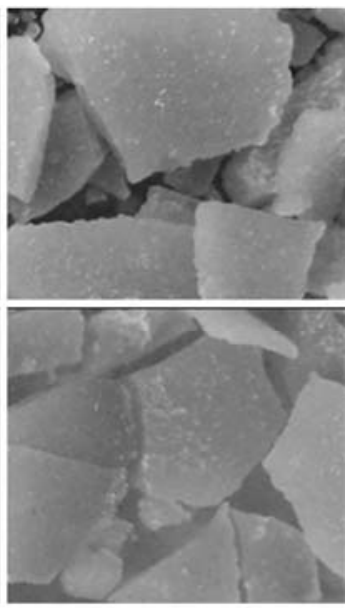

$\mathrm{pH} 10$

Figure 3. Colour of dried gel (top row) and humidified gel (bottom row). The pH indicates the equilibrium pH of hydrogel plus $\mathrm{CoCl}_{2}$ solution during impregnation.

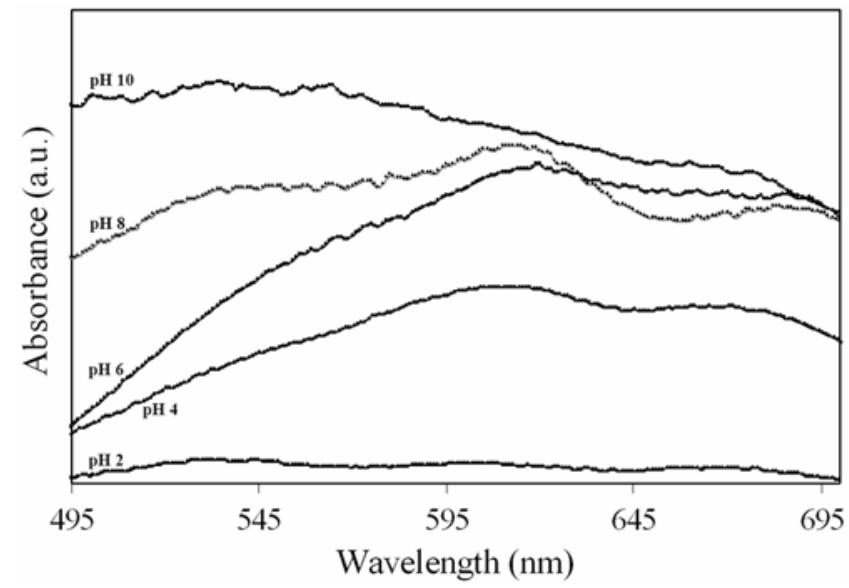

Figure 4. Visible spectra of different gels in their dry state. The $\mathrm{pH}$ indicates the equilibrium $\mathrm{pH}$ of hydrogel plus $\mathrm{CoCl}_{2}$ solution during impregnation of respective specimen.
$\mathrm{NH}_{3}$-ligand and hexaaminecobalt(II) complex is formed (Holleman-Wiberg 2001) as per:

$$
\begin{array}{cl}
{\left[\mathrm{Co}\left(\mathrm{H}_{2} \mathrm{O}\right)_{6}\right]^{2+}+6 \mathrm{NH}_{3} \rightarrow} & {\left[\mathrm{Co}\left(\mathrm{NH}_{3}\right)_{6}\right]^{2+}+6 \mathrm{H}_{2} \mathrm{O} .} \\
(\text { Pink }) & (\text { Yellow-Orange) }
\end{array}
$$

The $\left[\mathrm{Co}\left(\mathrm{NH}_{3}\right)_{6}\right]^{2+}$ complex can be easily oxidized to the cobalt(III) complex with a red-brown colour. During aging, this oxdidation takes place and hence the colour of pH 10 specimen after drying was reddish-brown. The gel also does not show any colour changing property with moisture adsorption.

Figure 4 shows the visible spectrum of different gels in their dry state. The $\mathrm{pH} 2$ gel shows no strong absorption at any specific colour region and appears nearly colourless. The $\mathrm{pH} \mathrm{4,} 6$ and 8 gels show absorption band within red region of the spectrum. Thus they appear blue in colour. In addition, $\mathrm{pH} 8$ gel shows another absorption band 
in green-yellow region. This green-yellow region absorption was strong in the $\mathrm{pH} 10$ gel and thus it appears reddish-brown in colour.

The moisture adsorption capacity is one of the most important properties of a desiccant. Figure 5(a) shows the water adsorption kinetic of $\mathrm{pH} 6$ gel measured at $80 \% \mathrm{RH}$ and $30^{\circ} \mathrm{C}$. The gel adsorbed about $40 \%$ moisture. The BET surface area of the dry gel was $580 \mathrm{~m}^{2} \mathrm{~g}^{-1}$. The high absorption capacity of the gel was due to its high surface area. The result indicates that the preparation method was efficient to produce a high specific surface area silica desiccant with good moisture absorption capacity.

One reason of high surface area gel formation may be the use of very low concentration of the cobalt chloride. It has been reported (Balkose et al 1998) that the pores of silica gel may be filled by the $\mathrm{CoCl}_{2}$ to some extent depending upon its concentration. The filling of pores lowers the adsorption capacity of the gel. Higher the concentration of $\mathrm{CoCl}_{2}$, greater the amount of pore filling.

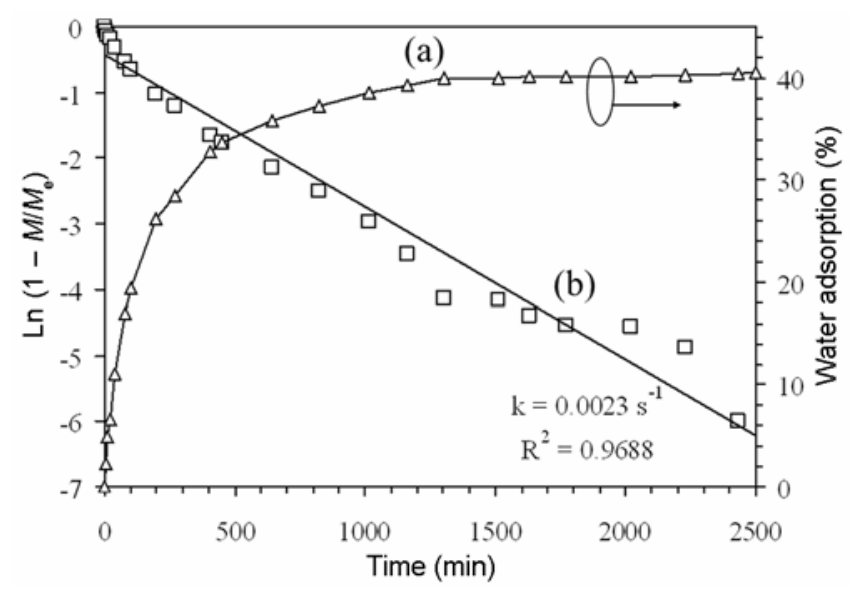

Figure 5. Adsorption kinetic curve (a) and linear dependence of $\ln \left(1-M_{\mathrm{t}} / M_{\mathrm{e}}\right)$ with time $(\mathrm{b})$, for water vapour adsorption on gel (pH 6 specimen) in $80 \% \mathrm{RH}$ and $30^{\circ} \mathrm{C}$.

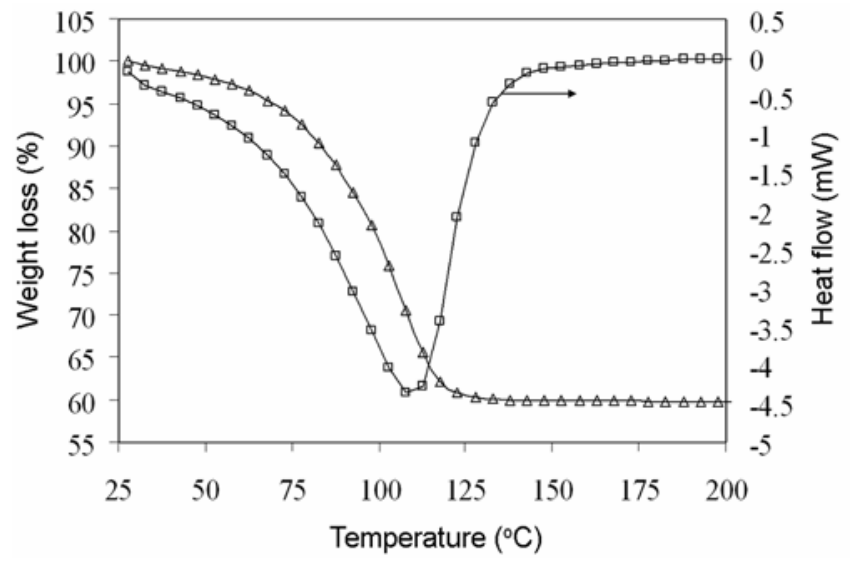

Figure 6. TG/DSC curves of silica gel (pH 6 specimen) after complete humidification.
The other reason may be the use of hydrogel for impregnation. The dispersion of cobalt chloride was uniform in hydrogel and thus a low concentration of salt was sufficient to impart blue colour in dry gel.

The kinetics of water vapour adsorption (figure 5(a)) shows the moisture sorption rate to be high during the initial stages and then gradually becoming low. This phenomenon can be analyzed using linear driving force (LDF) model (Zhong and Yang 1999; Cossarutto et al 2001). The model can be expressed as:

$$
1-\left(M_{\mathrm{t}} / M_{\mathrm{e}}\right)=e^{-k t},
$$

where $M_{\mathrm{t}}$ is the uptake at time $t, M_{\mathrm{e}}$ the equilibrium uptake and $k$ the rate constant. Figure 5(b) shows that the plot of $\ln \left(1-\left(M_{\mathrm{t}} / M_{\mathrm{e}}\right)\right)$ vs time is linear with the slope $(0.0023)$ equal to the rate constant $(k)$. The results again confirmed that the LDF model is suitable for the description of water vapour adsorption on the silica gel (Li et al 2007).

The desiccants are normally regenerated by heating. The regeneration characteristic of humidified gel $(\mathrm{pH} 6$ specimen) was studied using TG/DSC. Figure 6 shows the moisture desorption kinetics of the gel. The desorption starts from about $40^{\circ} \mathrm{C}$ with a slow rate and with an increased rate from about $75^{\circ} \mathrm{C}$. The maximum rate of desorption was at $107^{\circ} \mathrm{C}$ as shown by DSC endothermic peak. The moisture desorption completes by $130^{\circ} \mathrm{C}$. About $40 \%$ weight loss was shown by the specimen with a heat of vapourization of about $940 \mathrm{~J} \mathrm{~g}^{-1}$.

\section{Conclusions}

The humidity indicating silica desiccant was successfully prepared using rice husk ash waste material as a source for silica. The silica gel was prepared by acid neutralization of sodium silicate solution which was extracted from the ash through sodium hydroxide leaching. The silica hydrogel was impregnated with cobalt chloride solution of $0.0005 \mathrm{~mol} \mathrm{dm}^{-3}$ concentration at $\mathrm{pH}$ 6. The BET surface area of the gel was $580 \mathrm{~m}^{2} \mathrm{~g}^{-1}$. The desiccant was capable of adsorbing $40 \%$ moisture in $80 \% \mathrm{RH}$ at $30^{\circ} \mathrm{C}$. High adsorption capacity of the gel was due to high specific surface area and presence of very low concentration of $\mathrm{CoCl}_{2}$ in it. Regeneration of the desiccant could be possible by heating at $150^{\circ} \mathrm{C}$ for a few hours. The results of this study are useful for the preparation of low cost and highly efficient silica desiccant with improved safety from the point of very low cobalt content.

\section{Acknowledgement}

The authors are thankful to the Ministry of Environment and Forests, Government of India, New Delhi, for providing research grant vide sanction no. 19/50/2004 RE. 


\section{References}

Ahmed A E and Adam F 2007 Micropor. Mesopor. Mat. 103284 Balkose D, Ulutan S, Ozkan F C, Celebi S and Ulku S 1998 Appl. Surf. Sci. 13439

Brinker C J and Scherer G W 1990 Sol-gel science-the physics and chemistry of sol-gel processing (New York: Academic Press Inc) pp 839-880

Conradt R, Pimkhaokham P and Leela-Adisorn U 1992 J. NonCryst. Solids 14575

Cossarutto L, Zimny T and Kaczmarczyk J 2001 Carbon 39 2339

Cunha J C C and Canepa E M 1986; Research Project Report, Fundatec, Porto Alegre, R S, Goncalves M R F and Bergmann C P 2007 Constr. Build. Mater. 212059

Holleman-Wiberg 2001 Inorganic chemistry (San Diego: Academic Press) 1st edn, pp. 1475-1479

Iler R K 1979 Silica gels and powders-the chemistry of silica (New York: John Wiley and Sons) p. 462
Kalapathy U, Proctor A and Shultz J 2000 Bioresource Technol. 73257

Kamath S R and Proctor A 1998 Cereal Chem. 75484

Krishnarao R V and Godkhindi M M 1992 Ceram. Int. 18 243

Lender P W and Ruiter R 1990 Novel inorganic materials and heterogeneous catalysis. In Inorganic and metal-containing polymeric materials (eds) J E Sheats et al (New York: Plenum Press) pp. 187-195

Li X, Li Z, Xia Q and Xi H 2007 Appl. Therm. Eng. 27869

Liou T -H 2004 Mater. Sci. Eng. A364 313

Luan T C and Chou T C 1990 Ind. Eng. Chem. Res. 291922

Real C, Alcala M D and Criado J M 1996 J. Am. Ceram. Soc. 792012

Richardson H W 1993 Cobalt compounds, in Encyclopedia of chemical technology (eds) J I Kroschwitz and M Howe-Grant (New York: John Wiley \& Sons) Vol 6, p. 778

Yalcin N and Sevinc V 2001 Ceram. Int. 27219

Zhong L and Yang R T 1999 AIChE J. 145196 